\section{FRI0128 THE AGE DISTRIBUTION OF THE FOCAL HYPERINTENSITIES IN BRAIN MR IN PATIENTS WITH NEUROPSYCHIATRIC LUPUS}

${ }^{1} V$ Peterová, ${ }^{2} \mathrm{C}$ Dostál, 'Z Seidl, ${ }^{1} \mathrm{~T}$ Viták, ${ }^{1} \mathrm{~J}$ Obenberger, ${ }^{1} \mathrm{~J}$ Dane, ${ }^{2} \mathrm{M}$ Olejarová. ${ }^{1} \mathrm{MR}$ Department, General Faculty Hospital; ${ }^{2}$ SLE Research Group, Institute of Rheumatology, Prague 2, Czech Republic

\subsection{6/annrheumdis-2001.163}

\section{Background}

Objectives The authors determined the extent of central nervous system affection in patients with systemic lupus erythematosus (SLE) by the means of brain magnetic resonance (MR). The results were correlated with the controls and the results were compared statistically.

Methods Brain MR investigation was made by the routine protocol (T1 and T2 weighted images, FLAIR mode, transversal and sagittal scans) in 1,5T MR machine. 60 patients of all 3 groups (SLE, MS and controls) were investigated. The patients were divided into 3 groups due to the age distribution: 18-39, 40-49, 50 and more years.

Results In the patients with neuropsychiatric lupus the focal white matter hyperintensities in FLAIR mode were the most common findings. Their distribution was most often present in frontal and parietal lobes, where the average numbers of foci were 9,8, resp. 8,4. While in occipital and temporal lobes lobes the average numbers of foci were significantly lower, it appeared 2,2, resp. 2,3. Among SLE patients aged from 50 to 59 years the focal hyperintensities were the most common (the average number of foci was 8,4 ), which was statistically significant in comparison with both other age groups of patients. The distribution of focal hyperintensities in control group appeared different.

Conclusion MR method is the most sensitive method for establishing the central nervous system involvement in SLE patients. The number of focal hyperintensities was determined to be statistically different between SLE controls in all three age groups.

\section{REFERENCES}

1 Dostál C, Peterová V, Pale ková A. et al. Cerebral disease in SLE: selected autoantibodies and major central nervous system disorders. Lupus 1996;544

2 Hachulla E, Michon Pasdturel U, Leys D, et al. Cerebral magnetic resonance imaging in patients with or without antiphospholipid antibodies. Lupus 1998;7:12431

3 Kent L, Hayner DR, Longstreth WT, et al. The clinical efficacy of magnetic resonance imaging in neuroimaging. Ann Intern Med. 1994;120:856-61

4 Peterová V, Dostál C, Obenberger J, et al. MRI findings in patients with lupus erythematosus. Eur I Neurol. 1997:4:123

5 Peterová V, Dostál C, Seidl Z, et al. Postizení mozku u nemocných se SLE (Popis 2 prípado). Ceská Revmatologie 1998:275:178-81

6 Rovaris M, Viti B, Ciboddo G, et al. Brain involvement in systemic immune mediated diseases: magnetic resonance and magnetisation transfer imaging study. $J$ Neurol Neurosurg Psychiatry 2000;68:170-7

\section{FRI0129 LUPUS AND PURE RED CELL APLASIA}

GS Habib, W Saliba, P Froom. Internal Medicine B, Lady Davis Carmel Medical Center, Haifa, Israel

\subsection{6/annrheumdis-2001.164}

Background Pure Red CEll Aplasia (PRCA) is characterised by normochromic normocytic anaemia, reticulocytopenia and aplasia or severe hypoplasia of the red cell line with normal white cell and megakaryocyte lines in the bone marrow. ${ }^{1}$ PRCA may be associated with other conditions, ${ }^{2}$ but the association with systemic lupus erythematosus (SLE) is rare. Here we summarise our case and the previous cases of PRCA and SLE reported in the English literature.

Objectives To evaluate the clinical and laboratory features of all the patients reported with both SLE and PRCA.

Methods In addition to case, cases were identified from the English literature through a search using the Medline from the year 1966 till December 2000, and also through references of relevant publications.

Results Twenty-four cases, including our case were identified. The association between SLE and PRCA is relatively rare. However it may be underdiagnosed. In most of the cases SLE was diagnosed prior to or concomitantly with the diagnosis of PRCA. The clinical and laboratory features relevant to SLE in our patients are similar to the general patients of SLE, except for significantly less pleuritis and a trend for less nephritis, hallucinations, thrombopenia and leukopenia. Most of the patients had no clinical or laboratory activity at the time of PRCA diagnosis. In some patients as in the general patients with PRCA, inhibitory effect of the patient's serum against erythroid progenitor cells and against erythropoietin (EPO) were identified. In most of the patients PRCA responded to corticosteroid (CS) treatment, and in some of the non-responders other modalities of treatment like intravenous gammaglobulins and even EPO were helpful.

Conclusion The association between PRCA and SLE is relatively rare. The clinical and laboratory features relevant to SLE in our patients are similar to the general patients with SLE, and the spectrum of inhibitory effect on the erythroid progenitor cells and EPO are similar to the general patients with PRCA. Most patients had favourable response to CS treatment.

\section{REFERENCES}

1 Schmid JR, Kiely JM, Pease GL, Hargraves MM. Acquired pure red cell aplasia. Acta Haematol. 1963;30:325

2 Amus SS, Yunis AA. Aqcuired pure red cell aplasia. Am J Med. 1987;24:311-26

\section{FRI0130 RELATIONSHIP BETWEEN PRESENCE OF NEUROLOGICAL SYMPTOMS AND ACTIVITY OF SYSTEMIC LUPUS ERYTHEMATOSUS}

${ }^{1} \mathrm{~L}$ Ostanek, ${ }^{2} \mathrm{~K}$ Honczarenko, ${ }^{1} \mathrm{~K}$ Fischer, ${ }^{1} \mathrm{I}$ Fiedorowicz-Fabrycy. ${ }^{1}$ Rheumatology; ${ }^{2}$ Neurology, Pomeranian Academy of Medicine, Szczecin, Poland

\subsection{6/annrheumdis-2001.165}

Background According to many authors presence of neurological symptoms are features of disease activity in patients with systemic lupus erythematosus. Clinical observations very often do not confirm this hypothesis.

Objectives To assess if neurological symptoms correlate with disease activity in patients with systemic lupus erythematosus.

Methods The study was performed on 83 patients with SLE (77 women and 6 men), age 17-63 years mean age 33,8 yrs), disease duration was 1-30 years (mean 9,05 yr). Every subject was assessed at least two times by rheumatologist and neurologist during different stages of SLE activity. SLE activity was assess according to SLEDAI scale. Haematological, biochemistry and coagulation tests were performed for everyone. In some cases histopatolgical assessment of tissue samples were done. Electrophysiological tests (EEM, EMG, BAEP, VEP) and cerebral CT, MRI and SPECT scans were performed in subjects with neurological symptoms. All the subjects were tested for the presence of antinuclear antibodies, (ANA), anticardiolipin antibodies (aCL), anti-B2-glycoprotein antibodies and antiendothelial 
antibodies (AECA). Results of the mentioned tests were statistically evaluated.

Results

- No association has been found between presence of neurological symptoms and disease activity in patients with systemic lupus erythematosus

- Neurological symptoms were found significantly more frequently in subjects with high titer of $\operatorname{IgG}$ anticardiolipin antibodies and in patients with secondary antiphospholipid syndrome.

- There was a tendency for neurological symptoms to occur in patients with vascular complications.

Conclusion

\section{FRI0131 INCIDENCE OF RENAL FLARES AND THEIR PROGNOSTIC SIGNIFICANCE IN DIFFUSE PROLIFERATIVE GLOMERULONEPHRITIS}

${ }^{1} \mathrm{M}$ Mosca, ${ }^{1} \mathrm{~W}$ Bencivelli, ${ }^{1} \mathrm{R}$ Neri, ${ }^{2} \mathrm{~A}$ Pasquariello, ${ }^{2} \mathrm{R}$ Puccini, ${ }^{2} \mathrm{~V}$ Batini, ${ }^{1} \mathrm{~S}$ Bombardieri. ${ }^{1}$ Rheumatology Unit; ${ }^{2}$ Nephrology, University of Pisa, Pisa, Italy

10.1136/annrheumdis-2001.166

Background Diffuse Proliferative Glomerulonephritis (DPGN) is considered one of the most important factors influencing the long term prognosis of SLE patients. Renal flares are considered important risk factors influencing the outcome of renal involvement.

Objectives The aim of this study was to evaluate the occurrence of renal flares and their prognostic significance for the renal outcome in a population of SLE patients with DPGN.

Methods The clinical, laboratory and histological data of 91 SLE patients ( 8 males and 83 females) followed at the Rheumatology Unit of the University of Pisa, were retrospectively evaluated.

Results Fourty-nine patients (54\%) presented a renal flare a mean of 42 months after the renal biopsy. Twenty-eight flares $(57 \%)$ were proteinuric, twenty-one $(43 \%)$ were nephritic flares. A young age at the time of the renal biopsy and treatment with steroids alone, were significantly correlated with the occurrence of renal flares, furthermore a high Activity Index (AI >9) and the presence of karyorrhexis on renal histology were correlated with the occurrence of nephritic flares. A poor renal outcome occurred in $27 \%$ of the patients; serum creatinine levels at the time of renal biopsy, the presence of karyorrhexis and the composite Chronicity Index (CI) as well as all of its component on renal histology, the number of renal flares (both proteinuric and nephritic), the occurrence of nephritic flares and early proteinuric flares (i.e. in the first 17 months after the renal biopsy), were correlated with a poor renal outcome.

Conclusion In conclusion, the analysis of our patients has showed that nephritic flares and early proteinuric flares are important risk factors for the occurrence of a poor renal outcome. Since young patients with an elevated AI and karyorrhexis are at increased risk for renal flares, they should be candidated for a more aggressive and prolonged treatment.

\section{REFERENCES}

1 Moroni G, et al. Kidney Int. 1996;50:2047-53

2 Ponticelli C, et al. Lupus 1998;7:635-8

3 Ciruelo, et al. Arthritis Rheum. 1996;39:2028-34
FRI0132 DECREASED SERUM DNASE 1 ACTIVITY LEVELS IN SLE PATIENTS WITH ACTIVE DISEASE

${ }^{1}$ I Gunnarsson, ${ }^{1} \mathrm{~F}$ Guo-Zhong, ${ }^{2} \mathrm{HG}$ Mannherz, ${ }^{2} \mathrm{M}$ Napirei, ${ }^{2} \mathrm{~A}$ Gültekin, ${ }^{1} \mathrm{~J}$ Frostegård. ${ }^{1}$ Department of Rheumatology, Karolinska Hospital, Stockholm, Sweden; ${ }^{2}$ Abteilung Für Anatomie and Embryologie, Medizinishe Fakultät, Ruhr-Universität Bochum, Bochum, Germany

10.1136/annrheumdis-2001.167

Background DNASE 1 (deoxyribonuclease 1; EC 3.1.21.1) deficient mice have been shown to develop classical symptoms of Systemic Lupus Erythematosus (SLE) with anti-nuclear antibodies in the circulation. Low serum DNASE 1 activity has been reported in patients with SLE.

Objectives The aim of this study was to investigate serum DNASE 1 activity in SLE patients in relation to disease activity. In addition, the relationship between the DNASE 1 activity and renal involvement was analysed.

Methods Serum samples from fifty patients with SLE (ACR criteria), 39 females and 11 males, mean age 44, were analysed for DNASE 1 activity by the single radial enzyme-diffusion method (SRED) (Nadano et al., 1993). All sera were analysed on three separate occasions and the mean value $(\mathrm{pg} / \mathrm{ml})$ from the three experiments was used. Anti-dsDNA antibodies were detected by indirect IFL. SLE disease activity was assessed according to the Systemic Lupus Activity Measure (SLAM). A SLAM score of 7 or above was considered as high. Thirty $(60 \%)$ had high disease activity (SLE/active), the other 20 patients (SLAM <7) were classified as SLE/inactive. Twenty-six $(52 \%)$ of the 50 SLE patients had glomerulonephritis, in all cases confirmed by renal biopsy; the other 24 patients (48\%) had no clinical signs of renal involvement. The renal biopsies were classified according to the WHO classification. Six patients had WHO class II, 12 WHO class III/IV and 8 WHO class V.

Results Serum DNASE 1 levels were significantly lower in the SLE/active patient group as compared to the SLE/inactive patients $(12.4 \pm 3.8$ vs. $16.1 \pm 3.7 \mathrm{pg} / \mathrm{ml}$, mean $\pm S D, p<$ 0.005). Among the $20 \mathrm{SLE} /$ inactive patients, a trend towards lower serum DNASE 1 levels was noted in patients with renal involvement $(\mathrm{n}=9)(14.8 \pm 3.6 \mathrm{pg} / \mathrm{ml})$ as compared to patients without renal involvement $(\mathrm{n}=11)(17.1 \pm 3.5 \mathrm{pg} / \mathrm{ml}, \mathrm{p}=$ 0.06). However, in SLE/active patients, there was no significant difference in DNASE 1 levels between patients with and without renal involvement. There was no association between the levels of DNASE 1 activity and anti-dsDNA antibody titres. Twentyfive of the patients received prednisolone treatment. Among these patients, low levels of serum DNASE 1 activity were found to be associated with high dose prednisolone therapy $(\mathrm{r}=$ $0.552, \mathrm{p}<0.005)$.

Conclusion This study demonstrated low DNASE 1 levels to be associated with high disease activity in SLE patients and may represent a novel marker of disease activity independently of anti-dsDNA antibodies. Further studies are needed to clarify the role of DNASE 1 in SLE manifestations and disease development. 